\title{
Evidence of Nonadherence in Cases of Pseudoresistant Hypertension
}

This article was published in the following Dove Press journal:

Integrated Blood Pressure Control

\author{
João Marcos de Menezes \\ Zanatta (I) \\ Luciana Neves Cosenso- \\ Martin (D) \\ Valquíria da Silva Lopes \\ Jéssica Rodrigues Roma \\ Uyemura \\ Aleandra Marton Polegati \\ Santos \\ Manoel Ildefonso Paz Landim \\ Juan Carlos Yugar-Toledo (1D \\ José Fernando Vilela-Martin (ID \\ Internal Medicine Department, State \\ Medical School at Sao Jose Do Rio Preto \\ (FAMERP), Sao Jose Do Rio Preto, Sao \\ Paulo, Brazil
}

\begin{abstract}
Resistant hypertension (RH) is characterized by the use of three or more antihypertensive drugs without reaching the goal of controlling blood pressure (BP). For a definitive diagnosis of RH, it is necessary to exclude causes of pseudoresistance, including the white-coat effect, errors in BP measurement, secondary hypertension, therapeutic inertia, and poor adherence to lifestyle changes and pharmacological treatment. Herein, we report the history of a patient with long-standing uncontrolled BP, even when using seven antihypertensive drugs. Causes of secondary hypertension that justified the high BP levels were investigated, in addition to the other causes of pseudo-RH. In view of the difficult-to-control BP situation, it was decided to hospitalize the patient for better investigation. After 5 days, he had BP control with practically the same medications previously used. Finally, all factors related to the presence of pseudo-RH are discussed, especially poor adherence to treatment. Poor adherence to antihypertensive treatment is common in daily medical practice, and its investigation is of fundamental importance for better management of BP.
\end{abstract}

Keywords: hypertension, resistant hypertension, medication adherence

\section{Introduction}

Globally, hypertension is one of the most important risk factors of cardiovascular disease, stroke, chronic kidney disease, incapacity, and death. ${ }^{1}$ It is highly prevalent, and as such deserves attention from health professionals with regard to proper diagnosis and handling, with the aim of controlling blood pressure (BP) levels. Its prevalence is estimated to be around $31 \%$ in the Brazilian population when considering hypertension with BP values $\geq 140 / 90 \mathrm{mmHg}^{2,3}$ If we take into consideration the last US guideline that considers hypertension with BP levels $\geq 130$ / $80 \mathrm{mmHg}$, prevalence in the US population is $46 \%$, according to NHANES (2013-2016). ${ }^{1,4}$

Nowadays, even with modern antihypertensive therapy, there is a form of presentation of hypertension in which BP control is not achieved, known as resistant hypertension $(\mathrm{RH})$. It is defined as BP remaining above the recommended targets with the use of three or more antihypertensives of different classes, including a renin-angiotensin system blocker (angiotensin-converting enzyme inhibitor) or angiotensin-receptor blocker), a long-acting calcium channel blocker, and a longacting thiazide diuretic, all at maximum recommended and tolerated doses, with appropriate frequency, dosage, and proven adherence by the patient. ${ }^{5,6}$

RH individuals represent a group at higher risk of target-organ damage, cardiovascular morbidity, and mortality. In 2012, the Brazilian Society of Cardiology
Martin

Internal Medicine Department, State Medical School at Sao Jose Do Rio Preto (FAMERP), 5416 Avenida Brigadeiro Faria Lima, Sao Jose Do Rio Preto, SP, I5090000, Brazil

Tel +55 I7 320I-5727

Email vilelamartin@uol.com.br

Integrated Blood Pressure Control 2021:14 9-17 
issued its first position on $\mathrm{RH}$, which included recommendations for diagnosis, evaluation, and treatment. ${ }^{7}$ Since then, a large number of studies on RH have improved our understanding of its pathogenesis, evaluation, and treatment, and new statements of position have been published. 5,6 Nevertheless, the real prevalence of $\mathrm{RH}$ remains still controversial, mainly because of the difficulty in identifying cases of "pseudoresistance" 8,9

For correct diagnosis of $\mathrm{RH}$, it is necessary to rule out factors that may interfere with BP control, such as accuracy of $\mathrm{BP}$ measurement, white-coat effect, adherence to pharmacological and nonpharmacological treatment, inadequate therapeutic regimen, and therapeutic inertia, in addition to the use of medications that increase BP and causes of secondary hypertension. ${ }^{5,6}$ As such, the first step in the correct diagnosis of true RH is to exclude these factors.Among them, pharmacological nonadherence is a well-known and highly prevalent behavioral cause of poor BP control. ${ }^{10-15}$

Medication adherence is defined as the process by which patients take their medications as prescribed, and comprises three components: initiation, implementation, and discontinuation. ${ }^{16}$ Initiation is the time from prescription until the first dose of the medication is taken. The implementation of the doses corresponds to day-to dayexecution, ie, it reflects the daily use of medications. In turn, discontinuation represents the end of therapy, when the patient does not take the next dose and the treatment is interrupted thereafter. Finally, persistence is the length of time between initiation and the last dose immediately preceding discontinuation. ${ }^{16}$ Thenceforward, three major types of deviations from given instructions can occur and are particularly common: noninitiation, short persistence, and poor execution. ${ }^{15,17}$ Generally, poor execution is a typical consequence of occasional forgetfulness or negligence, results in more or less prolonged periods of treatment interruptions characterizing unintentional nonadherence, and represents a majority of cases. Usually, unintentional nonadherence results from a lack of understanding or other educational, mental, or physical personal problems. On the other hand, intentional nonadherence is an active process in which an individual actively or consciously chooses to forego prescribed antihypertensive drugs (either to skip some doses, modify, or discontinue). ${ }^{15,17,18}$ All these aspects of adherence to medication have a direct and major influence on the quality of BP control in RH, the most critical being of course noninitiation and a lack of persistence. ${ }^{15}$ In the specific case of antihypertensive drugs in pseudo- $\mathrm{RH}$, intentional nonadherence easily escapes detection and can be costly to diagnose and to correct. ${ }^{17}$

Nowadays, indirect and direct methods are used for assessment of nonadherence to BP-lowering drugs. Indirect methods are less invasive and cheaper. They include patient interviews, patient diaries, questionnaires, self-reports, pill count, assessment of the patient's response, measurement of physiological markers, review of prescriptions, and electronic medication monitoring. ${ }^{15,17,19,20}$ In turn, direct methods are more invasive and expensive, and include the direct observation of patients during the use of lowering-BP drugs and measurement of levels of antihypertensive drugs or their metabolites in the blood or in the urine. ${ }^{15,17,19,20}$ This case report discusses several stages of clinical investigation and complementary exams that must be performed, including nonadherence assessment, which are fundamental tasks for the diagnosis of pseudoresistance to treatment.

\section{Case Report}

The patient was a 56-year-old white woman with a 4-year history of hypertension with uncontrolled BP. In addition, she had had Hashimoto's thyroiditis for about 10 years. She denied a history of smoking or drinking. She was taking valsartan (320 $\mathrm{mg} /$ day $)$, hydrochlorothiazide (75 mg/day), methyldopa (1,500 mg/day), atenolol (100 $\mathrm{mg} /$ day), spironolactone ( $25 \mathrm{mg} /$ day), and levothyroxine sodium $(300 \mu \mathrm{g} / \mathrm{day})$ at initial consultation. She was intolerant to angiotensin-converting enzyme inhibitors because of cough and amlodipine due to lower-limb edema. The patient told us that she was taking all the medications correctly. The degree of adherence was determined using the eight-item Morisky Medication Adherence Scale (MMAS8) translated into Brazilian Portuguese, and the patient was considered to have high adherence (eight points) on this test. ${ }^{21-23}$

Her physical examination revealed BP 230/160 mmHg (mean of three measures) in both arms, heart rate $80 \mathrm{bpm}$, body mass index $29.3 \mathrm{~kg} / \mathrm{m}^{2}$, and waist circumference $94 \mathrm{~cm}$. The BP measure in the lower limbs did not show a significant difference in relation to upper limbs. She had no abnormalities of the heart, lungs, or abdomen. According to initial complementary exams, the patient presented fasting glycemia $101 \mathrm{mg} / \mathrm{dL}$, sodium $142 \mathrm{mEq} / \mathrm{L}$, potassium 4.4 $\mathrm{mEq} / \mathrm{L}$, creatinine $0.8 \mathrm{mg} / \mathrm{dL}$, estimated glomerular filtration rate (CKD-EPI) $89.3 \mathrm{~mL} / \mathrm{min} / 1.73 \mathrm{~m}^{2}$, normal routine urine, microalbuminuria $230 \mathrm{mg} / 24 \mathrm{~h}$ (normal $<30 \mathrm{mg} / 24$ h), total cholesterol $148 \mathrm{mg} / \mathrm{dL}$, HDL cholesterol $38 \mathrm{mg} / \mathrm{dL}$, 
LDL cholesterol $86 \mathrm{mg} / \mathrm{dL}$, and triglycerides $122 \mathrm{mg} / \mathrm{dL}$. The 24-hour urinary sodium measure was $164 \mathrm{mEq} / \mathrm{L}$ (ideal level $<100 \mathrm{mEq} / \mathrm{L}$ ). Other exam results were thyroid-stimulating hormone $40.89 \mathrm{mU} / \mathrm{L}$, free $\mathrm{T}_{4} 0.75 \mathrm{ng} / \mathrm{dL}$, parathyroid hormone $58.86 \mathrm{pg} / \mathrm{mL}$ (normal 10-65 pg/mL), vitamin D $30.8 \mathrm{ng} / \mathrm{mL}$, and serum calcium $9.2 \mathrm{mg} / \mathrm{dL}$ (normal 8-10 mg/dL).

Electrocardiography was normal, with sinus rhythm and heart rate of $74 \mathrm{bpm}$. Echocardiography showed structural and functional normality. Ambulatory BP monitoring (ABPM) revealed 24-hour mean BP of 204/130 mmHg, awake BP of 207/133 mmHg, and 193/122 mmHg BP during sleep, with attenuated nocturnal dipping in systolic and diastolic BP. The patient had hypertensive retinopathy (grade 2 Keith-Wagener-Barker classification). All investigations for secondary hypertension were negative. Therefore, primary hyperaldosteronism, renovascular hypertension, renal disease, obstructive sleep apnea, pheochromocytoma, acromegaly, and Cushing's disease were excluded, as shown in Table 1. Four weeks prior to investigation for hyperaldosteronism, her thiazide diuretic, renin-angiotensin system blocker, and mineralocorticoidreceptor antagonist were stopped for screening this condition, in accordance with guidelines. ${ }^{4-6}$

During outpatient follow-up, hydrochlorothiazide was exchanged for chlorthalidone $(25 \mathrm{mg} /$ day $)$, and nitrendipine $(20 \mathrm{mg} /$ day) was added to her antihypertensive treatment. Nevertheless, the patient had several BP elevations of up to $290 / 180 \mathrm{mmHg}$ and a hospital admission with hypertensive encephalopathy, even with the use of valsar$\tan (320 \mathrm{mg} /$ day $)$, chlortalidone (25 $\mathrm{mg} /$ day), nitrendipine

Table I Results of Investigation of Secondary $\mu$ Hypertension

\begin{tabular}{|l|l|l|}
\hline & Result & Reference \\
\hline Aldosterone & $12.5 \mathrm{ng} / \mathrm{dL}$ & $3.4-27.3 \mathrm{ng} / \mathrm{dL}$ \\
Plasma renin activity (PRA) & $1.6 \mathrm{ng} / \mathrm{mL} / \mathrm{h}$ & $0.5-6 \mathrm{ng} / \mathrm{mL} / \mathrm{h}$ \\
Aldosterone:PRA ratio & 7.81 & $<27$ \\
Urinary metanephrine & $212.2 \mu g / 24 \mathrm{~h}$ & $<280 \mu g / 24 \mathrm{~h}$ \\
Urinary normetanephrine & $417.9 \mu \mathrm{gg} / 24 \mathrm{~h}$ & $<732 \mu g / 24 \mathrm{~h}$ \\
Plasma adrenaline & $10.6 \mathrm{pg} / \mathrm{mL}$ & $<90 \mathrm{pg} / \mathrm{mL}$ \\
Plasma noradrenaline & $100.6 \mathrm{pg} / \mathrm{mL}$ & $<460 \mathrm{pg} / \mathrm{mL}$ \\
Plasma dopamine & $30.1 \mathrm{pg} / \mathrm{mL}$ & $<30 \mathrm{pg} / \mathrm{mL}$ \\
Cortisol & $8.04 \mu \mathrm{gg} / \mathrm{dL}$ & $6.2-19.4$ \\
Growth hormone & $0.12 \mathrm{ng} / \mathrm{mL}$ & $<3.61 \mathrm{ng} / \mathrm{mL}$ \\
IFGI (somatomedin) & $116 \mathrm{ng} / \mathrm{mL}$ & $123-406 \mathrm{ng} / \mathrm{mL}$ \\
Renal ultrasonography & Normal & - \\
Renal Doppler velocimetry & Normal & - \\
Polysomnography & Normal & - \\
\hline
\end{tabular}

(20 mg/day), methyldopa (1,500 mg/day), atenolol (100 $\mathrm{mg} /$ day), and spironolactone (150 mg/day). Moreover, she was also using diazepam (10 mg/day) and levothyroxine sodium (300 $\mu \mathrm{g}$ /day). On hospital discharge, methyldopa was exchanged for clonidine $(600 \mu \mathrm{g} / \mathrm{day})$, and hydralazine $(150 \mathrm{mg} /$ day $)$ was added to the therapy regimen.

A careful interview and investigation of nonadherence was performed, and given that the patient stated that she had taken all the prescribed medications, a hypothesis of intestinal absorption disturbance was arrived at as the cause of the lack of control of hypertension and thyroid function. However, all functional, anatomic, and histopathologic investigation for malabsorption syndromes gave negative results (upper digestive endoscopy and colonoscopy, both with normal biopsies, antitissue transglutaminase IgA and IgG antibodies and antigliadin IgA antibodies were nonreagents upon testing for celiac disease).

Considering the difficulty in controlling the hypertension and due to the high cardiovascular risk presented by the patient (target-organ damage), the team opted to hospitalize her for the purpose of observing her evolution and performing other investigations. The usual biochemical tests were normal. She maintained her previous weight. During the hospitalization, there was a progressive control of BP levels around the fifth day of admission with administration of the same drugs previously used by the patient (valsartan $320 \mathrm{mg} /$ day, chlortalidone $25 \mathrm{mg} /$ day, nitrendipine $20 \mathrm{mg} /$ day, atenolol $100 \mathrm{mg} /$ day, clonidine $(600 \mu \mathrm{g} /$ day, hydralazine $(150 \mathrm{mg} /$ day, and spironolactone $150 \mathrm{mg}$ / day); Figure 1). She was discharged after 10 days with controlled BP. The patient was referred for psychiatric evaluation, where she was diagnosed with recurrent depressive disorder and medicated. Subsequently, she was referred for follow-up with psychology. About 30 days after discharge, BP remained high with the same drugs used in hospital.

\section{Discussion}

In the present report, we discuss the case of a middleaged female patient with a history of uncontrolled hypertension in the long term and all the diagnostic steps involved in the investigation of $\mathrm{RH}$ with the exclusion of confounding factors, including causes of pseudoresistance. It is common to find individuals with elevated BP in an outpatient clinic specialized in hypertension, even when using three or more antihypertensive drugs, a fact that fulfills the initial definition of $\mathrm{RH}$ and 


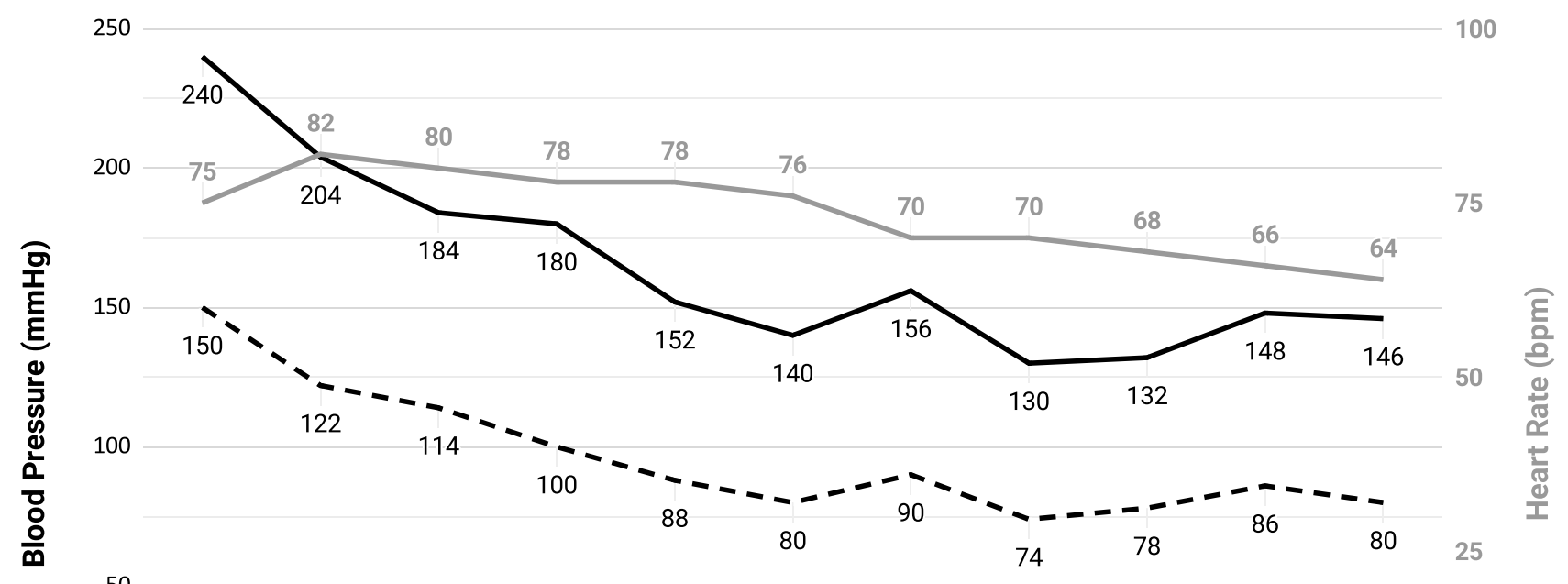

50

$\begin{array}{llllllllllll}0 & 1 & 2 & 3 & 4 & 5 & 6 & 7 & 8 & 9 & 10 & 0\end{array}$

Days

Figure I Evolution of systolic blood pressure (solid line), diastolic blood pressure (dashed line), and heart rate (gray line) in hospital.

is compatible with the description of the patient, who was using five antihypertensive drugs. Therefore, for true RH diagnosis, it was necessary to exclude causes of pseudoresistance following diagnostic investigation (Table 2). Pseudo-RH is attributed to six principal etiologies - white-coat effect, errors in BP measurement, failure of drug prescription, use of drugs that increase BP, poor adhesion to lifestyle changes, and pharmacological treatment - besides the presence of secondary hypertension causes.

The first step in investigation of $\mathrm{RH}$ would be to request $\mathrm{ABPM}$ or home $\mathrm{BPM}$, in order to evaluate the white-coat effect as a cause of pseudoresistance. The ABPM of our patient showed elevated BP levels during 24 hours awake and during sleep, a fact that excluded the white-coat effect. The nocturnal dipping was attenuated, and the BP means in all the periods were above the recommended levels, according to guidelines. Studies have shown that $30 \%-50 \%$ of hypertensive individuals considered resistant in fact show a white-coat effect. ${ }^{24,25}$ Moreover, ABPM is important in performing therapeutic adjustment, detecting nondipper patterns (prognostic marker in RH), and introducing nightly doses of antihypertensive drugs (chronotherapy) to reverse the adverse pattern of nocturnal dipping. ${ }^{5,6,25-27}$ All these situations highlight the need to request ABPM or home BPM for individuals suspected of RH.

Secondly, errors in accuracy of BP measurements, which are mainly related to technical issues and the use of inadequately sized cuffs, should be observed carefully to avoid overestimating BP. ${ }^{5,6,28,29}$ Bhatt et al showed that approximately $33 \%$ of uncontrolled $\mathrm{RH}$ individuals were falsely identified as having $\mathrm{RH}$ based on triage BP measurements. ${ }^{30}$ The following procedures are fundamental steps for attaining the best accuracy in BP measurement. ${ }^{3-6,29}$ Measurements should be taken with a calibrated aneroid sphygmomanometer or automatic digital device. The cuff should be placed so that the lower edge is $3 \mathrm{~cm}$ above the elbow crease and the bladder centered over the brachial artery. A cuff compatible with the circumference of the arm should be used, considering that these patients are generally obese or overweight. Preferably, the arm should be bare and supported with the BP cuff positioned at heart level. A mean of three BP measurements taken in a sitting position after 5-10 minutes of rest should be performed. For aneroid sphygmomanometry, consider the phase I and V (disappearance) Korotkoff sounds to identify systolic and diastolic BP, respectively. Also, where an aneroid device is being used, the inflation pressure must reach $30 \mathrm{mmHg}$ above 
Table 2 Steps in the Diagnostic Assessment of Resistant Hypertension to Exclude Pseudoresistance to Treatment

\begin{tabular}{|l|l|}
\hline & To Investigate \\
\hline I. ABPM/HBPM & White-coat effect \\
\hline 2. BP-measurement technique & $\begin{array}{l}\text { Measure errors } \\
\text { Cuff size }\end{array}$ \\
\hline 3. Medical prescription & $\begin{array}{l}\text { Inadequate combinations } \\
\text { Inappropriate doses }\end{array}$ \\
\hline 4. Drugs that increase BP & $\begin{array}{l}\text { Nonsteroidal anti-inflammatories } \\
\text { Corticosteroids } \\
\text { Sympathomimetics } \\
\text { Amphetamines } \\
\text { Oral contraceptives } \\
\text { Cyclosporine, tacrolimus } \\
\text { Recombinant human erythropoietin } \\
\text { Licorice } \\
\text { Cocaine }\end{array}$ \\
\hline 5. Nonadherence & $\begin{array}{l}\text { Lifestyle changes } \\
\text { Pharmacological treatment }\end{array}$ \\
\hline 6. Secondary hypertension & Specific tests \\
\hline 7. General biochemical exams & $\begin{array}{l}\text { Sodium, potassium } \\
\text { Creatinine (and eGFR) } \\
\text { Glycemia (and HbA } \\
\text { Lipids for diabetes) } \\
\text { Routine urine } \\
24-h o u r \text { urinary sodium } \\
\text { Microalbuminuria } \\
\text { TSH, free thyroxine }\end{array}$ \\
\hline
\end{tabular}

Abbreviations: ABPM/HBPM, ambulatory BP monitoring/home BP monitoring; $B P$, blood pressure; eGFR, estimated glomerular filtration rate (CKD-EPI); $\mathrm{HbA}_{\mathrm{Ic}}$ glycated hemoglobin; TSH, thyroid-stimulating hormone.

the level at which the radial pulse is extinguished, and a cuff-deflation rate of $2 \mathrm{mmHg}$ per beat must be used. A minimum of 1-2 minutes is recommended between readings to avoid venous congestion. BP should be measured in both arms to detect possible differences due to peripheral vascular disease.

In sequence, other causes that should be evaluated for a pseudoresistance diagnosis are failures in drug prescription with inadequate drug and dose combinations, ${ }^{28,31}$ especially subutilization of appropriate diuretics. ${ }^{32}$ Nevertheless, in the evolution of this case, the patient was using seven drugs with adequate doses, among them a thiazide diuretic (chlorthalidone) and spironolactone, which is considered the fourth drug for RH treatment. ${ }^{5,6}$ On the other hand, a report of drug-induced side effects or a clinical response to antihypertensive drugs may be proof that drugs have been taken. ${ }^{33}$ Therefore, in the present case, a $\beta$-blocker was prescribed; however, the patient's ambulatory heart rate was $>70 \mathrm{bpm}$, ie, she did not present bradycardia, possibly indicating nonadherence to treatment. Additionally, during the hospitalization, her heart rate reduced to $<70 \mathrm{bpm}$, indicating clinical response to $\beta$-blocker use (Figure 1).

Drugs that increase BP should always be investigated and discontinued when possible. Other factors that are strong predictors of hypertension, such as excessive ingestion of salt, obesity, and physical inactivity, should also be monitored and lifestyle changes implemented. ${ }^{5,6,29}$ A DASH (dietary approaches to stop hypertension) diet, weight loss, and physical activity are important tools for improved BP control, but adherence is a difficult barrier to overcome. ${ }^{3-6}$ In the present report, the patient was overweight, and 24-hour urinary sodium was above the ideal level, showing that she had poor adherence to lifestyle changes.

During the investigation stages of true $\mathrm{RH}$, it is also necessary to rule out causes of secondary hypertension. The most common etiologies were evaluated and discounted. chronic kidney disease was also ruled out, since renal function was normal (eGFR $89.3 \mathrm{~mL} / \mathrm{min} / 1.73 \mathrm{~m}^{2}$ ). In relation to biochemical tests performed since the basal evaluation, an important alteration in thyroid function was observed, indicating that it had not responded to the reposition with thyroid hormone. Thyroid hormones act on the cardiovascular system, promoting impact on cardiac function. Hypothyroidism is associated with decreased cardiac output because of impaired relaxation of vascular smooth muscle and decreased nitric oxide production. This leads to systemic vascular resistance increase and consequently increased diastolic BP. ${ }^{34}$ Nevertheless, from our point of view, hypothyroidism could not explain the high BP levels as the likely cause of secondary hypertension, since BP was controlled during the hospitalization, suggesting nonadherence to the use of medications, including the thyroid hormone.

In spite of the fact that the patient had no gastroenterology signals or symptoms, malabsorption syndrome was considered a possible justification for no responses to thyroid or hypertension treatment. However, the complementary investigation showed no alterations in functional or histopathologic gastrointestinal tract exams. Therefore, considering the high cardiovascular risk (target-organ damage and previous hypertensive emergency), ${ }^{35}$ the patient was admitted, in order to perform better investigation and improve BP control. As reported earlier, BP levels reduced progressively during the first 5 days, with BP controlled. From our perspective, this was evidence that 
the patient was not taking the drugs correctly, neither for hypertension nor hypothyroidism. Additionally, the lowsodium diet during hospitalization may have contributed to the reduction in $\mathrm{BP}$. On the other hand, the BP control while in hospital also removes other reasons for the extremely elevated BP, including possible causes of secondary hypertension. Although a careful interview with the patient had been carried out to investigate adherence and she had stated that she was using the drugs correctly (high adherence to MMAS8 scale), ${ }^{21-23}$ there were probably errors in the use of the medications, due to forgetfulness, confusion or even the option of not using them, which is why we requested a follow-up with psychiatry/psychology. The patient was diagnosed with a psychiatric disorder, which could explain the nonadherence to lifestyle changes and pharmacological treatment.

$\mathrm{RH}$ is difficult to diagnose in daily medical practice; therefore, it is necessary to evaluate all the possible causes, including poor adherence to treatment. Drug nonadherence is highly relevant in cases of pseudo-RH. Indeed, when BP does not decrease despite the prescription of at least three antihypertensive drugs, including a diuretic, physicians face two major challenges: is the patient not responding to therapy, or is the patient not taking drugs as recommended, characterizing a nonadherer? True resistance to pharmacotherapy is relatively uncommon, a situation that led us to ask if drugs work in individuals who do not take them. ${ }^{17}$ Drug nonadherence is highly prevalent in patients with pseudo-RH, and it must also be excluded before definitive diagnosis of $\mathrm{RH} .^{10,11}$ Studies have shown that $50-80 \%$ of patients have no complete adherence. ${ }^{8,10,11}$ Our group has demonstrated that about
$86 \%$ have presented poor adherence to both medication and nonmedication treatment, and emotional factors were the most reported (69.12\%) among patients' reasons for nonadherence to treatment ${ }^{36}$ a fact also observed in two European centers, which demonstrated that emotional impact was an important predictor of BP control. ${ }^{37}$

Several methods are used for assessment of adherence to BP-lowering drugs, but they have different degrees of accuracy. Figure 2 shows the indirect (noninvasive) and direct (invasive) methods used for evaluation of adherence to antihypertensive drugs. ${ }^{15,17,20}$ During the investigation of adherence to BP-lowering drugs, a careful patient interview is very important, including questionnaires and pill count, but questionnaires are known to be inaccurate, and in recent evaluations the ability of doctors to detect nonadherence is very low, compatible with another case report. ${ }^{17}$ On the other hand, therapeutic drug monitoring (TDM) is considered direct, invasive, and expensive, but most accurate method for evaluating intentional nonadherence. TDM measures the drug or metabolite (biomarkers) concentration in body fluids (blood or urine). ${ }^{15,17,20}$ For this objective, liquid chromatography-mass spectrometry analysis can be used. ${ }^{15,17,20}$ A recent study evaluated if there were concordance between TDM and self-reported adherence in individuals with $\mathrm{RH}$, and no concordance was found, pointing to the low accuracy of the indirect method. ${ }^{12}$ However, TDM needs to be realized with the informed consent of patients and tends to induce whitecoat adherence, ie, patients tend to increase adherence a few days before and after a consultation. ${ }^{15,17,20}$ This method is not available in our center.

\section{Non-invasive Methods}

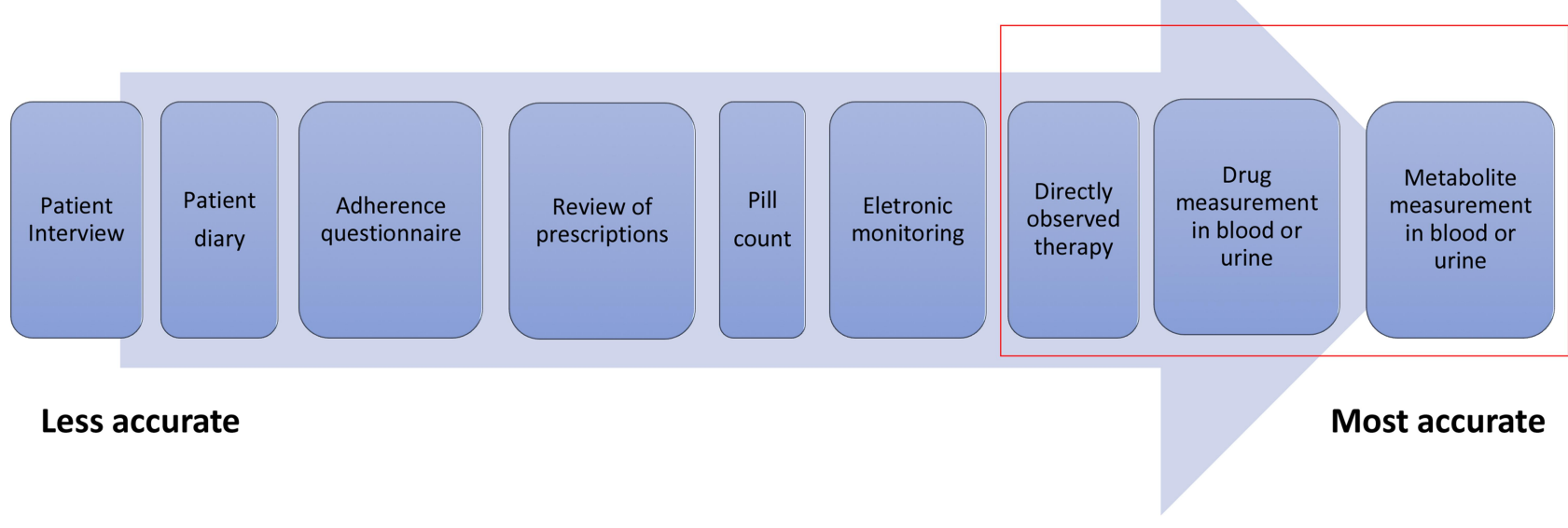

Figure 2 Methods of evaluation of drug adherence according to accuracy. The last three selected methods are considered invasive. 
In following up this case, we used other direct methods to evaluate adherence to BP-lowering drugs, eg, directly observed therapy, which was originally developed for treatment of tuberculosis. ${ }^{38}$ With this method, ${ }^{15,17,20}$ the pharmacodynamic effect of administered BP-lowering drug is relatively easy to measure, simply by observing BP over time, since the peak effect on BP is within the first 3-4 hours, with gradual dissipation over the next 24-48 hours, quite suitable for diagnosis of intentional nonadherence to antihypertensive drugs. We advocate that hospitalization be used as a substitute, very similar to the original method, and this was the method that showed the nonadherence in our case.

Pharmacological nonadherence is related to several factors, such as the large pill, dosing complexity, costs, adverse reactions with multidrug antihypertensive regimens, bad patient-clinician relationships, and clinician inertia with reduced insistence on adherence when individuals present consistently suboptimal adherence. ${ }^{39,40}$ Other factors related to poor adherence are mainly old age and low education. Older individuals and those with low education have difficulty understanding the importance of following the advice of health professionals, as well as remembering the recommended dosage and correct times to take the pills. . $^{810,11,39,40}$ Our patient had not completed elementary education, which is in line with the literature.

Drug associations and the assistance of a multidisciplinary team capable of guiding appropriate use of medication and monitoring changes in lifestyle are often able to minimize this issue. ${ }^{3,4}$ Transparent clinician-patient discussion without blame, observation of prescription refills and tablet counts, hospitalization, and if possible biochemical assays of medications or their metabolites in urine or plasma must be part of nonadherence investigation. It is important to highlight that there is no gold standard for investigation of adherence, and to overcome each method's limitations, a combination of measures should be used. ${ }^{15,17,20}$ Therefore, multifactorial conditions can be mitigated through healtheducation policies that value the instruction of individuals, using clear language and amusing material, if necessary, to explain the consequences of uncontrolled BP resulting from poor adherence to treatment. An effective doctor-patient relationship also presents an important strategy for winning over the patient and convincing them of the need for therapy, in addition to family involvement in the line of care, especially in the case of elderly patients.

Our patient did not have characteristics compatible with the typical presentation of $\mathrm{RH}$, which occurs predominantly in men aged $>55$ years, in individuals who are black, have diabetes, are obese, or have stage 3 or higher chronic kidney disease. ${ }^{5,6,29}$ Considering the elevated BP levels in the office and on 24-hour ABPM, the optimized therapeutic strategies used in the prehospitalization treatment with consequent lack of BP control and the assessment of nonadherence using the inpatient (directly observed therapy method), with evident reduction in BP and heart rate, we can conclude that we were facing a case of pseudo-RH, due to the patient's lack of adherence to drug treatment on a daily basis.

\section{Consent Statement}

We confirm that the patient provided informed consent for the case details to be published, and institutional approval was not required.

\section{Acknowledgments}

The authors wish to thank DE Morisky, who gave permission for use of the MMAS8 for this study.

The MMAS 8 scale, content, name, and trademarks are protected by US copyright and trademark laws. Permission for use of the scale and its coding is required. A license agreement is available from MMAR, Donald E. Morisky, ScD, ScM, MSPH, 294 Lindura Court, Las Vegas, NV, USA,dmorisky@gmail.com.

\section{Disclosure}

The authors report no conflicts of interest in this work.

\section{References}

1. Virani SS, Alonso A, Benjamin EJ, et al. Heart Disease and Stroke Statistics-2020 Update: a Report from the American Heart Association. Circulation. 2020;141(9):e139-e596. doi:10.1161/CIR.00 00000000000757.

2. Picon RV, Fuchs FD, Moreira LB, Riegel G, Fuchs SC. Trends in prevalence of hypertension in Brazil: a systematic review with metaanalysis. PLoS One. 2012;7(10):e48255. doi:10.1371/journal.pone.00 48255.

3. Malachias M, Plavnik FL, Machado CA, Malta D, Scala LCN, Fuchs S. 7th Brazilian Guideline of Arterial Hypertension. Chapter 1 concept, Epidemiology and Primary Prevention. Arq Bras Cardiol. 2016;107(3 Suppl 3):1-16. doi:10.5935/abc.20160151.

4. Whelton PK, Carey RM, Aronow WS, et al. 2017 ACC/AHA/AAPA/ $\mathrm{ABC} / \mathrm{ACPM} / \mathrm{AGS} / \mathrm{APhA} / \mathrm{ASH} / \mathrm{ASPC}$ NMA/PCNA guideline for the prevention, detection, evaluation, and management of high blood pressure in adults: executive summary: a report of the American college of cardiology/american heart association task force on clinical practice guidelines. Hypertension. 2018;71(6):e13-e115. doi:10.1161/ HYP.0000000000000065.

5. Yugar-Toledo JC, Moreno Júnior H, Gus M, et al. Brazilian Position Statement on Resistant Hypertension - 2020. Arq Bras Cardiol. 2020;114(3):576-596. doi:10.36660/abc.20200198. 
6. Carey RM, Calhoun DA, Bakris GL, et al. Resistant hypertension: detection, evaluation, and management a scientific statement from the american heart association. Hypertension. 2018;72(5):e53-e90. doi:10.1161/HYP.0000000000000084.

7. Alessi A, Brandão AA, Coca A, Cordeiro AC, Nogueira AR. First Brazilian position on resistant hypertension. Arq Bras Cardiol. 2012;99(1):576-585. doi:10.1590/s0066-782x2012000700002.

8. Burnier M, Wuerzner G, Struijker-Boudier H, Urquhart J. Measuring, analyzing, and managing drug adherence in resistant hypertension. Hypertension. 2013;62(2):218-225. doi:10.1161/ HYPERTENSIONAHA.113.00687.

9. Ceral J, Habrdova V, Vorisek V, Bima M, Pelouch R, Solar M. Difficult-to-control arterial hypertension or uncooperative patients? The assessment of serum antihypertensive drug levels to differentiate non-responsiveness from non-adherence to recommended therapy. Hypertens Res. 2011;34(1):87-90. doi:10.1038/hr.2010.183.

10. Hameed MA, Tebbit L, Jacques N, Thomas M, Dasgupta I. Nonadherence to antihypertensive medication is very common among resistant hypertensives: results of a directly observed therapy clinic. J Hum Hypertens. 2016;30(2):83-89. doi:10.1038/jhh.2015.38.

11. Schulz M, Krueger K, Schuessel K, et al. Medication adherence and persistence according to different antihypertensive drug classes: a retrospective cohort study of 255,500 patients.Int $J$ Cardiology. 2016;220:668-676. doi:10.1016/j.ijcard.2016.06.263.

12. Avataneo V, De Nicolò A, Rabbia F, et al. Therapeutic drug monitoring-guided definition of adherence profiles in resistant hypertension and identification of predictors of poor adherence. $\mathrm{Br} \mathrm{J}$ Clin Pharmacol. 2018;84(11):2535-2543. doi:10.1111/bcp.13706.

13. Durand H, Hayes P, Morrissey EC, et al. Medication adherence among patients with apparent treatment-resistant hypertension: systematic review and meta-analysis. J Hypertens. 2017;35(12):23462357. doi:10.1097/HJH.0000000000001502.

14. Hayes P, Casey M, Glynn LG, et al. Prevalence of treatment-resistant hypertension after considering pseudo-resistance and morbidity: a cross-sectional study in Irish primary care. Br J Gen Pract. 2018;68 (671):e394-e400. doi:10.3399/bjgp18X696221.

15. Burnier M. Drug Adherence in Hypertension. Pharmacol Res. 2017;125(Pt B):142-149. doi:10.1016/j.phrs.2017.08.015.

16. Vrijens B, De Geest S, Hughes DA, et al. A new taxonomy for describing and defining adherence to medications. Br J Clin Pharmacol. 2012;73 (5):691-705. doi:10.1111/j.1365-2125.2012.04167.x.

17. Ruzicka M, Hiremath S. Can drugs work in patients who do not take them? The problem of non-adherence in resistant hypertension. Curr Hypertens Rep. 2015;17(9):579. doi:10.1007/s11906-015-0579-4.

18. Mukhtar O, Weinman J, Jackson SHD. Intentional non-adherence to medications by older adults. Drugs Aging. 2016;220(3):668.

19. Hayen A, Bell K, Glasziou P, Neal B, Irwig L. Monitoring adherence to medication by measuring change in blood pressure. Hypertension. 2010;56(4):612-616. doi:10.1161/HYPERTENSIONAHA.110.153817.

20. Rabbia F, Fulcheri C, Di Monaco S, et al. Adherence to antihypertensive therapy and therapeutic dosage of antihypertensive drugs. High Blood Press Cardiovasc Prev. 2016;23(4):341-345. doi:10. 1007/s40292-016-0158-z.

21. Morisky DE, Ang A, Krousel-Wood M, Ward HJ. Predictive validity of a medication adherence measure in an outpatient setting. J Clin Hypertens. 2008;10(5):348-354. doi:10.1111/j.1751-7176.2008.07572.x.

22. Berlowitz DR, Foy CG, Kazis LE, et al. For the SPRINT study research group. impact of intensive blood pressure therapy on patient-reported outcomes: outcomes results from the SPRINT study. $N$ Engl J Med. 2017;377(8):733-744. doi:10.1056/NEJMoa1611179.

23. Bress AP, Bellows BK, King JB, et al. For the SPRINT Research Group and the SPRINT Economics and Health Related Quality of Life Subcommittee. Cost-Effectiveness of Intensive versus Standard Blood Pressure Control. N Engl J Med. 2017;377(8):745-755. doi:10.1056/NEJMsa1616035.
24. de la Sierra A, Segura J, Banegas JR, et al. Clinical features of 8295 patients with resistant hypertension classified on the basis of ambulatory blood pressure monitoring. Hypertension. 2011;57(5):898-902. doi:10.1161/HYPERTENSIONAHA.110.168948.

25. Salles GF, Cardoso CR, Muxfeldt ES. Prognostic influence of office and ambulatory blood pressures in resistant hypertension. Arch Intern Med. 2008;168(21):2340-2346. doi:10.1001/archinte.168.21.2340.

26. Hermida RC, Ayala DE, Mojon A, Fernandez JR. Effects of time of antihypertensive treatment on ambulatory blood pressure and clinical characteristics of subjects with resistant hypertension. Am J Hypertens. 2010;23(4):432-439. doi:10.1038/ajh.2009.260.

27. Hermida RC, Ayala DE, Fernandez JR, et al. Bedtime blood pressure chronotherapy significantly improves hypertension management. Heart Fail Clin. 2017;13(4):759-773. doi:10.1016/j.hfc.2017.05.010.

28. Judd E, Calhoun DA. Apparent and true resistant hypertension: definition, prevalence and outcomes. J Hum Hypertens. 2014;28 (8):463-468. doi:10.1038/jhh.2013.140.

29. Sarafidis PA, Georgianos P, Bakris GL. Resistant hypertension-its identification and epidemiology. Nat Rev Nephrol. 2013;9(1):51-58. doi:10.1038/nrneph.2012.260.

30. Bhatt H, Siddiqui M, Judd E, Oparil S, Calhoun D. Prevalence of pseudoresistant hypertension due to inaccurate blood pressure measurement. J Am Soc Hypertens. 2016;10(6):493-499. doi:10.1016/j. jash.2016.03.186.

31. Muxfeldt ES, de Souza F, Salles GF. Resistant hypertension: a practical clinical approach. J Hum Hypertens. 2013;27(11):657-662. doi:10.1038/jhh.2013.34.

32. Garg JP, Elliott WJ, Folker IM, Black HR. RUSH University Hypertension Service. Resistant hypertension revisited: a comparison of two university-based cohorts. Am J Hypertens. 2005;18 (5Pt.1):619-626. doi:10.1016/j.amjhyper.2004.11.021.

33. Kociánová E, Václavík J, Tomková J, et al. Heart rate is a useful marker of adherence to beta-blocker treatment in hypertension. Blood Press. 2017;26(5):311-318. doi:10.1080/08037051.2017.1346458.

34. Udovcic M, Pena RH, Patham B, Tabatabai L, Kansara A. Hypothyroidism and the Heart. Methodist Debakey Cardiovasc J. 2017;13(2):55-59. doi:10.14797/mdcj-13-2-55.

35. Williams B, Mancia G, Spiering W, et al. 2018 ESC/ESH Guidelines for the management of arterial hypertension: the Task Force for the management of arterial hypertension of the European Society of Cardiology (ESC) and the European Society of Hypertension (ESH). Eur Heart J. 2018;39(33):3021-3104. doi:10.1093/eurheartj/ ehy339.

36. Dosse C, Cesarino CB, Martin JF, Castedo MC. Factors associated to patients' noncompliance with hypertension treatment. Rev Lat Am Enfermagem. 2009;17(2):201-206. doi:10.1590/s0104-11692009000 200010.

37. Pappaccogli M, Di Monaco S, Coralie G, et al. Predictors of blood pressure control in patients with resistant hypertension after intensive management in two expert centres: the Brussels-Torino experience. Blood Press. 2019;28(5):336-344. doi:10.1080/08037051.2019. 1633908.

38. Bayer R, Wilkinson D. Directly observed therapy for tuberculosis: history of an idea. Lancet. 1995;345(8964):1545-1548. doi:10.1016/ s0140-6736(95)91090-5.

39. Van der Laan DM, Elders PJM, Boons CCLM, Beckeringh JJ, Nijpels G, Hugtenburg JG. Factors associated with antihypertensive medication non-adherence: a systematic review. J Hum Hypertens. 2017;31:687-694. doi:10.1038/jhh.2017.48.

40. Elliott WJ. What factors contribute to the inadequate control of elevated blood pressure? J Clin Hypertens. 2008;10(suppl 1):20-26. doi:10.1111/j.1524-6175.2007.08028.x. 


\section{Publish your work in this journal}

Integrated Blood Pressure Control is an international, peer-reviewed open-access journal focusing on the integrated approach to managing hypertension and risk reduction. Treating the patient and comorbidities together with diet and lifestyle modification and optimizing healthcare resources through a multidisciplinary team approach constitute key features of the journal. This journal is indexed on
American Chemical Society's Chemical Abstracts Service (CAS) The manuscript management system is completely online and includes a very quick and fair peer-review system, which is all easy to use. Visit http://www.dovepress.com/testimonials.php to read real quotes from published authors. 